2017-07-03

\title{
Systemic-attachment formulation for families of children with autism
}

\author{
Hudson, M
}

http://hdl.handle.net/10026.1/10263

10.1108/AIA-02-2017-0005

Advances in Autism

Emerald

All content in PEARL is protected by copyright law. Author manuscripts are made available in accordance with publisher policies. Please cite only the published version using the details provided on the item record or document. In the absence of an open licence (e.g. Creative Commons), permissions for further reuse of content should be sought from the publisher or author. 


\section{eemeraldinsight}

\section{Advances in Autism}

Systemic-attachment formulation for families of children with autism

Mark Hudson, Rudi Dallos, Rebecca McKenzie,

\section{Article information:}

To cite this document:

Mark Hudson, Rudi Dallos, Rebecca McKenzie, (2017) "Systemic-attachment formulation for families of children with

autism", Advances in Autism, Vol. 3 Issue: 3, pp.142-153, https://doi.org/10.1108/AIA-02-2017-0005

Permanent link to this document:

https://doi.org/10.1108/AIA-02-2017-0005

Downloaded on: 02 August 2017, At: 12:32 (PT)

References: this document contains references to 46 other documents.

To copy this document: permissions@emeraldinsight.com

The fulltext of this document has been downloaded 11 times since 2017*

\section{Users who downloaded this article also downloaded:}

(2017),"Autism and healthcare", Advances in Autism, Vol. 3 Iss 3 pp. 115-124 <a href="https://doi.org/10.1108/

AIA-02-2017-0004">https://doi.org/10.1108/AIA-02-2017-0004</a>

(2017),"Transition tools and access to adult primary care", Advances in Autism, Vol. 3 Iss 3 pp. 131-141 <a href="https:// doi.org/10.1108/AIA-02-2017-0006">https://doi.org/10.1108/AIA-02-2017-0006</a>

Access to this document was granted through an Emerald subscription provided by

\section{For Authors}

If you would like to write for this, or any other Emerald publication, then please use our Emerald for Authors service information about how to choose which publication to write for and submission guidelines are available for all. Please visit www. emeraldinsight.com/ authors for more information.

\section{About Emerald www.emeraldinsight.com}

Emerald is a global publisher linking research and practice to the benefit of society. The company manages a portfolio of more than 290 journals and over 2,350 books and book series volumes, as well as providing an extensive range of online products and additional customer resources and services.

Emerald is both COUNTER 4 and TRANSFER compliant. The organization is a partner of the Committee on Publication Ethics (COPE) and also works with Portico and the LOCKSS initiative for digital archive preservation.

*Related content and download information correct at time of download. 


\title{
Systemic-attachment formulation for families of children with autism
}

\author{
Mark Hudson, Rudi Dallos and Rebecca McKenzie
}

\author{
Mark Hudson is a Clinical \\ Psychologist at Sheffield \\ Children's Hospital, \\ Sheffield, UK. \\ Rudi Dallos is based at the \\ University of Plymouth, \\ Plymouth, UK. \\ Rebecca McKenzie is a \\ Lecturer at the University of \\ Plymouth, Plymouth, UK.
}

\begin{abstract}
Purpose - Case formulation has gained increasing prominence as a guide to intervention across a range of clinical problems. It offers a contrasting orientation to diagnosis and its value is considered in the context of clinical work with autistic spectrum disorders (ASD). The purpose of this paper is to argue that case formulation integrating attachment, systemic and narrative perspectives offers a valuable way forward in assisting people with the diagnosis and their families.

Design/methodology/approach - The literature on ASD and related conditions is reviewed to examine levels of co-morbidity, consider the role of parental mental health difficulties and explore the issues inherent with current approaches to diagnosis.

Findings - ASD is found to have a high level of co-morbidity with other difficulties, such as anxiety and insecure attachment. Research findings, alongside the authors own clinical experience, are developed to suggest that formulation can allow the possibility of early intervention based on a holistic appraisal of the array of difficulties present prior to a diagnosis.

Originality/value - It is argued that the use of this systemic-attachment formulation approach could offset the exacerbation in ASD and related conditions, and deterioration in families' mental health, whilst they face long waiting times for a diagnosis.
\end{abstract}

Keywords Autism, Attachment, Autism spectrum disorder, Formulation, Family systems, Systemic therapy Paper type Viewpoint

\section{Introduction}

There has been an increase in the use of diagnosis relating to a variety of conditions, both in terms of the amount and variety of problems that are diagnosed. For example, there has been an exponential rise in the number of cases of children diagnosed with attention deficit hyperactivity disorder (ADHD), personality disorders, eating disorders and autistic spectrum disorders (ASD) (Kelleher et al. , 2000). The last has moved from a relatively rare diagnosis originally suggested by Kanner (1943) to epidemic proportions (Fombonne, 2001). Why has this occurred? One argument is that clinicians have become much better at diagnosing the condition, which for many people, now over 1 per cent of the general population, previously went undiagnosed. This may be true, but there could be other explanations, such as selective attention to signs of the condition, over-zealous use of the diagnosis and pressure from parents and schools to offer a diagnosis to "explain" the behaviours of children who are challenging to others.

Families of children with a diagnosis of ASD present a complex array of needs. Children with ASD have core impairments in social communication and interaction, and behavioural flexibility (American Psychiatric Association, 2013). Autism is widely accepted to have a genetic component, and family members of children with ASD are likely to share some traits with their children (Sasson et al., 2013). High levels of co-morbidity with other mental health conditions is reported in between 63 and 96 per cent of children with ASD (Van Steensel et al., 2013), who are highly likely to present with secondary problems including anxiety and depression, sleeping difficulties, digestive problems and aggressive behaviour. In particular, "meltdowns" (severe tantrum-like outbursts) are widely reported among these children. Although young people with ASD are able to form secure attachments to their caregivers, they have also been
Received 25 February 2017

Revised 16 April 2017

27 April 2017

Accepted 28 April 2017 
found to show significantly higher levels of insecure and disorganised attachment styles than comparison groups (Naber et al., 2007; Van IJzendoorn et al., 2007). Among people diagnosed with an intellectual disability (ID), issues with social information processing, executive functioning and language have been suggested to affect their ability to understand and regulate emotions, form supportive relationships, and turn to others as a "safe haven" (Schuengel and Jansen, 2006).

The impairments associated with ASD, alongside autistic traits and mental health difficulties among family members, are likely to impact on the parent-child relationship. For example, children with ASD have a reduced tendency to seek, respond to and evoke social experience, they can struggle to read their parents' intentions and accept soothing, and may not signal their needs clearly (Gaigg, 2012; Mandy and Lai, 2016). In response to these challenges, parents must become extraordinarily attuned to their child's feelings, in order to help them make progress. However, parents of children with ASD have been reported to have fewer needs met by services than parents of children with other disabilities, and 50 per cent or more have been reported to have elevated levels of psychological distress (Mazefsky et al., 2008; Demir et al., 2008; Siklos and Kerns, 2006). The lack of support offered to parents, alongside the stress associated with caring for their child, makes it much harder for parents to mentalize and understand their child's needs (Slade, 2009). Self-reports by parents of children with ASD also suggest that where their ability to cope is compromised, due to psychological problems and high levels of stress, maladaptive coping strategies in the children are exacerbated (Nikmat et al., 2008).

The relationship between parents' psychological resources and the development of their child's profile of ASD and related difficulties is complex, and likely to reflect a reciprocal interaction of multiple biological and environmental risk factors over time (Crittenden et al., 2014; Mandy and Lai, 2016). Whilst the psychological difficulties experienced by parents are often attributed to the stress of parenting a child with ASD, there is evidence that some parents have encountered trauma and abuse in their own histories (Roberts et al., 2013), and that in 40-70 per cent of cases their mental health difficulties predate the birth of the child (Daniels et al., 2008; Jokiranta et al., 2013; Mazefsky et al., 2008). Unresolved trauma in parents is implicated in the development of insecure attachment patterns, which among parents of a child with ASD have been associated with reduced relational and functional levels in their child (Seskin et al., 2010). Hence, psychological distress and maladaptive coping skills among parents may interact with their child's autism-related difficulties, leading to a negative cycle of escalating distress, characterised by attachment insecurity. Whilst parents' resources are an important area to consider, it is important to note that in the above studies, parents' mental health difficulties did not consistently predate the birth of the child, and not all parents had insecure attachment patterns or experiences of trauma, showing that these difficulties sit alongside a range of other risk factors which influence how the symptoms associated with ASD are expressed.

In this paper, we consider current issues associated with the diagnosis of ASD, including the impact of waiting times and the lack of attention paid to relational and systemic factors. We provide case examples of families interviewed as part of clinical work and ongoing research, and offer an alternative model of assessment and early intervention based on a case formulation approach.

\section{Diagnosis and seeking support}

It is at a point of crisis that many families seek referral to an "autism pathway" for diagnostic assessment. Families often tell a story of how they noticed problems, but had to wait for a diagnosis to confirm that the problems were medically recognised (McKenzie and Dallos, 2017). Frequently, they also recount how they were not believed, felt blamed for the problems, or were accused of being "bad parents". These stories are extremely poignant and a typical response is to emphasise that more services should be made available and earlier in the process. We hold much sympathy with the distress and anxiety experienced by families, but it is questionable whether more and earlier diagnosis is simply the answer. A critical question that applies to ASD, but also other conditions, is whether a diagnosis clearly indicates which clinical interventions are needed. An individual case formulation approach would propose that each person and their 
family have a unique profile of ASD, related difficulties and family/relational dynamics in which the person with ASD lives (Johnstone and Dallos, 2013).

When considering the overlap between ASD and other mental health diagnoses such as ADHD and ID (Gillberg, 2010; Giltaij et al., 2015, 2016), we are particularly interested in the considerable difficulty reported by clinicians in distinguishing between problems associated with autism and those stemming from attachment difficulties (Moran, 2010). We suggest that children diagnosed with autism can be seen to fall into one of three categories, those with ASD and secure attachment, those with ASD and insecure attachment and those who have been misdiagnosed, whose core problems stem from attachment difficulties (McKenzie and Dallos, in press). Issues for clinicians largely arise from the current diagnostic emphasis on making discrete distinctions between conditions, where the difficulties are so intertwined that no such distinction is possible. Difficulties also arise from the assumption that conditions such as ASD and ADHD have a biological basis and symptoms, therefore, cannot reflect contextual, relational factors.

Families are often waiting for two years or longer for a diagnosis (Siklos and Kerns, 2006) and during this time there is a risk of developing entrenched cycles of psychological distress and challenging behaviour. Current clinical procedures mean that it is difficult for families to access intervention programmes prior to a diagnosis being made. This lengthy waiting period often precludes early intervention, despite the fact that there is ample evidence that early intervention can have positive outcomes and early symptoms need not be deterministically related to later deficits (Le Couteur et al., 1996). In addition, the limited support received by families is often disjointed, with different services focussing on the problems presented by different family members. Formulation centres on assessment of need rather than identification of specific symptoms associated with a condition (Johnstone and Dallos, 2013) and provides an opportunity to address the lengthy wait many families experience prior to diagnosis. There is in principle, therefore, no reason why initial assessments based on formulation and systemic approaches to treatment could not be used as soon as families are referred.

\section{Diagnosis and its relation to systemic formulation}

Whilst not intending to provoke an extended debate regarding the merits of formulation vs diagnosis, we suggest that there are several key issues related to a purely diagnostic approach to understanding autism. A fundamental problem is that the presence of a "pure" form of autism, separate from other psychological conditions such as anxiety and attachment insecurity, is very rare (Gillberg, 2010). In addition to this, the diagnosis of ASD does not account for differences in the family circumstances, trans-generational patterns, and relationship with the school and other systems, which all impact on the young person and those around them. A further question is "what happens to families where a child has been suspected of having autism but does not gain a diagnosis?" Here, the child will also be left with difficulties that go unexplained, which may result in the family seeking a different diagnosis, such as ADHD. Alternatively, the family may go elsewhere to get the diagnosis of autism, or they may feel misunderstood, leading to a deterioration in their problems.

Another issue is that the focus of diagnosis is mainly on intra-psychic processes, for example, "communication impairment" is largely seen as residing within the child. However, communication is a relational process and how parents respond will influence this "impairment". Recent studies indicate that training parents to be able to attend and respond more effectively to subtle cues from their child with ASD, leads to improvement in their problems (Green et al., 2015; Pickles et al., 2016; Poslawsky et al., 2015). Where issues such as attachment difficulties, trauma and unresolved grief are present in the family context, components of systemic therapy may lead to the following changes: changes in how family members view the problems, their relationships and their attachment process; changes in how family members relate to each other; changes in how families view and manage family lifecycle transitions. These three areas are central to a systemic - attachment-based formulation of autism and we suggest that aside from the accuracy of the diagnosis, families will show significant differences in these areas which need to be taken into account in clinical interventions with them. The advantages of focussing on attachment are also indicated by research from the field of ID, 
which has shown that existing behavioural approaches are less effective when the person with ID has a disrupted caregiving history, due to the significance of attachment relationships for affect regulation, and the fact that the person might not find relationships rewarding (Schuengel et al., 2013).

\section{A systemic-attachment formulation of autism}

Though frequently referred to as distinct theories, attachment and systemic theory are inextricably linked. Bowlby (1988) used systems theory to conceptualise attachment as a dynamic system based upon feedback to regulate the emotional state of connection between infant and caregiver. The instinct to form attachments for survival and safety was what motivated family systems. He was interested in how the family system could be de-stabilised by an attachment shock, such as a loss, illness or injury. His ideas lead towards a formulation of problems such as ASD impacting on, and being impacted by, the family's attachment dynamics and challenges. Similarly, Crittenden et al. (2014) suggest a focus on understanding what type of intervention is most appropriate rather than categorising symptoms according to diagnostic criteria. This involves a "family functional formulation" in which a detailed understanding of the relationships around the "patient" is arrived at through assessment of attachment strategies, history of exposure to danger for each family member and areas of family conflict.

Attachment theory, however, has essentially been employed as a dyadic model although Bowlby's aims were broader. Wider attachment models such as Marvin and Stewart (1990) have shown how a threat can throw a family system into a state of anxiety and insecurity. How the system attempts to rectify the destabilisation may result in regaining security in its members or an aggravation of insecurity, distress and pathology. Relevant to this is the process that happens in a family along its journey towards a diagnosis of ASD. Once the child is identified as "different" some families may be able to accommodate and adapt to find ways to cope with the challenges. For other families this may arouse anxiety, self-criticism and foster an increase in insecurity in the system. The families' response may in turn be influenced by the level of support the family has, the parents' own childhood experiences and other factors such as illness, financial problems, or the safety of their living situation.

A core concept in family systems theory is that family lifecycle transitions represent important points of challenge and opportunities for families. In effect these challenges can be seen as revisions necessary to the attachment dynamics. In families with a child who has a disability, the expected developmental pathway or family lifecycle may be disrupted, which can be linked to feelings of loss. For example, some parents become fearful that their child may not be able to cope with the transition to starting school and decide to home educate their child. This impacts on the child's social development, for example forming friendships, and in turn can aggravate problems of communication and social interaction. It may also impact on the parents' lives in terms of work, career and their own social life, for example, if one or other parent gives up work to stay at home to educate their child. Parents need support from their own family systems and may try to draw on support from their grandparents for childcare. Our clinical experience has suggested, however, that there are commonly differences in parents' and grandparents' beliefs and opinions about what the cause of the autistic problems are and what is best to do.

For parents, the diagnosis of autism for their child can provide a feeling of relief, help them to resolve feelings of blame and guilt, enable them to accept their child, and provide access to the support that they need (Midence and O'Neill, 1999). However, in our experience, we have also seen a process whereby once a diagnosis is given, families adopt a genetic framework and become attentive to indications of autism elsewhere in the family system. In one family, the mother became convinced following the diagnosis of her daughter that her own mother and father also had autism. This added support to her belief that her parents were inadequate at providing care and support for her and her child. McKenzie and Dallos (2016) also describe a process whereby the diagnosis of autism can come to totally define a person's identity, and all aspects of their behaviour are attributed to underlying impairments associated with being "autistic", which are typically viewed as lifelong and not amenable to intervention. Consequently, 
it can become difficult to disentangle what is linked to autism and what might be attributable to other aspects of the person's personality or stage of development.

Many challenges for a family also become evident at the leaving home transition stage. Parents may be fearful that their autistic child will not be able to cope with independent living. Though these fears are understandable, they may become communicated as an anxiety, which in turn reduces the young adult's confidence and autonomy. This can lead to an escalating feedback loop with the result that the transition is delayed or abandoned (Rhodes, 2003). Alternatively, having received little support and coped with challenging behaviour for many years, parents may be ready for their child to leave home, at an earlier point than would be typical in the family lifecycle. However, this can be associated with guilt and fear of judgement from others, transitions being delayed, and an increase in maladaptive relational patterns.

Such family processes are in turn shaped by the parents' own childhood attachment experiences. The internal working models developed will orient to towards either a reliance on self and minimisation of emotions, or an exaggeration of emotions and need for others. In the general population, broadly 60 per cent of people display secure attachments which show a balance of these two patterns (Bakermans-Kranenburg and van IJzendoorn, 2009). Therefore, approximately 40 per cent of parents with a child with a diagnosis of autism would be expected to employ insecure patterns, which impact on how they negotiate important family transitions. There is considerable evidence, however, that more than 40 per cent of these parents have insecure attachment patterns due to mental health problems, trauma and loss (McKenzie and Dallos, in press).

A further important area of difficulty for many families are the so called "meltdowns". A systemic formulation attempts to track the sequential, circular steps that maintain such patterns of interaction. Though frequently attributed predominantly to ASD, the meltdowns show similarities to patterns found in ADHD, conduct disorders and more generally "tantrums" in young children. Our research indicates that parents' attachment systems are activated in these parents (Montague et al., in press) and for some parents, memories of painful childhood attachment events and traumas become activated:

When my son starts screaming it triggers those feelings of stress that I had when my mother used to scream (at me) [...] that kind of brings it all back, it's sort of like triggering, which is why I think that I find it particularly stressful [...] there you know there's a link between the past and the present. (Mandy - mother of a boy with the diagnosis of autism; Montague et al., in press).

A systemic-attachment formulation can reveal that as with Mandy above, the cycle can be aggravated by interference from traumatic memories, which can lead to parents entering a flight-fight mode of anxious arousal, making it hard to manage their child's demands. Solomon and George (2011) have similarly described how parental sense of helplessness contributes to the exacerbation of difficulties in children.

The negotiation of these changes and the impact of the eventual diagnosis are shaped by the narratives or discourses that the families draw on. For example, the neurodiversity movement in ASD has come to emphasise that autism is not abnormal, or an illness, but a "different" and equally viable way of being a person. However, in cases of severe autism this discourse may be harder to contemplate and a sense of loss and grief may be prevalent. Alongside this parents may feel a sense of blame at suggestions that they may in some way be causing problematic cycles. This poses a dilemma for an attachment-systemic formulation, which may at first sight appear to be parent-blaming. This is not our intention and we suggest that attachment theory holds the central premise that not only is the child's need for protection instinctual, but so is the parents' caregiving. Parents very rarely wish to hurt or damage their children and are typically trying to do their best. Byng-Hall (1998) has contributed the idea of corrective and replicative scripts to emphasise parent's positive intentions - how parents might want their families to be similar or different to what they experienced as children. An exploration of corrective and replicative scripts is extremely important in formulating how and why parents respond as they do in difficult cycles, such as meltdowns.

It has also been our clinical and research experience (Montague et al., in press) that many parents are not confident that what they experienced in their own childhood helps them to be parents themselves and they become doubly confused about how to apply what they have learnt to a 
child who appears to be "different" and challenging. As an example, Mandy described her mother as "an undiagnosed schizophrenic" who behaved abusively and made her feel terrified. When Mandy's own child showed anger and shouted at her, these memories were triggered, causing arousal in her own body alongside emotions triggered by her child's anger. In addition, Mandy was confused by some of the contradictory advice given in books about behaviour management and autism. This left her feeling powerless and frozen while her child screamed at her. Her replicative script was to show aggression to her child as her mother had done, but this may have left her child feeling uncontained and lacking discipline and boundaries. This cycle is shown in Figure 1.

In all families, the parents may at times disagree on the best way to deal with their child and the problems that arise. Their parenting approaches are under-pinned by their own attachment styles and differences may be complementary, for example where one parent is more concerned with fostering independence, and the other is more emotionally nurturing. Differences in their attachment orientations, however, may become polarised in the face of the challenges posed by a child with a diagnosis of ASD. A dismissive attachment orientation suggests that the child should be held responsible for their actions, encouraged to be independent and not encouraged to show negative feelings. In contrast, a pre-occupied attachment orientation in a parent emphasises that the child's emotional needs are paramount and they should not be overly encouraged to be independent. In the case of a child with autism, each parent may feel that the contradictory information and advice available supports their own view, leading them to become more polarised in their positions. This can promote a process of "triangulation", where a child becomes drawn into taking sides in their parents' disagreements and their ability to parent is impeded (Dallos and Vetere, 2012).

\section{Process of developing a systemic-attachment formulation}

Formulation within a systemic-attachment model involves movement through a series of levels, each requiring increasing trust and safety, from consideration of current relational patterns that are maintaining the distress, to family narratives and attachment strategies, and intergenerational patterns that are being brought into current relationships (Dallos and Vetere, 2009; Dallos, 2016). Initial discussion with the family focusses on the impact of autism in family life, the concerns

\section{Figure 1 Formulation of a meltdown cycle}

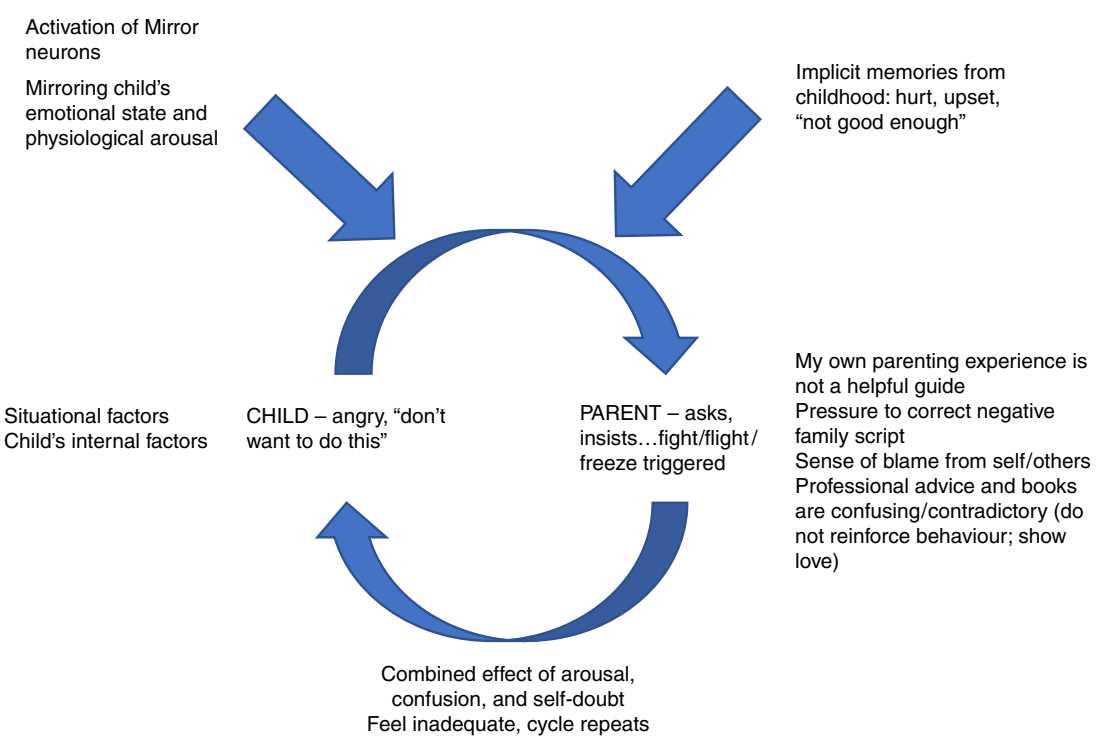

Source: Adapted from Montague et al. (in press) 
shared by different family members, and the feelings that are generated, such as anger, frustration and helplessness, as well as success when things are going well. A core problem can then be mapped out by locating it in a specific situation, and drawing out a cycle of the thoughts, feelings, actions and intentions of each family member (Dallos and Vetere, 2014). This can lead to discussion of ways in which the problematic cycle can be altered and provides a roadmap towards desired changes in the future.

Emotional sculpting can be used to illustrate family relationships and feelings, where each family member picks a button to represent themselves and then positions it to express the differences between them in terms of distance and closeness, family patterns and the differences observed over time, e.g. prior to the diagnosis of autism, current family relationships and the ideal configuration in the future. Self-autism mapping (McKenzie and Dallos, 2016) is also used to engage the child in a discussion about which aspects of themselves are affected by autism, and which are not. This involves introducing the child to two figures representing "Just me" and "Me and autism", as well as a space in between for the parts of themselves which they are "Not sure" about (see Figure 2). This activity allows exploration of the families' beliefs about which aspects of their child's behaviour are attributable to autism, and which aspects might be separate and "normal" for a typically developing child of their age.

Following this, the therapist draws out a genogram with the family, and focusses on the similarities and differences in attachment patterns and attachment needs for each family member, the way they cope with threat and comfort one another, the attachment significance of events (such as transitions), and parenting styles. If the family gives permission and there is sufficient safety in the relationship, the focus can then move onto intergenerational processes, and the way in which the parents' history may influence how they respond to the child with autism in the present. This may involve discussion of "autistic-like" traits in the family, parental mental health difficulties, experience of domestic violence, and the parents' own upbringing, including any experiences of emotional unavailability, abuse or neglect. As opposed to finding fault in the parents, this allows them to de-shame by recognising how their current coping strategies make sense and can be understood in the context of their early experience. It also involves identifying corrective and replicative scripts, and the way parents' childhood experiences may not have provided them with the care and nurturance needed to parent their children as they wish to in the present.

\section{Case example: Ben and his family}

Ben was a 13-year-old boy with mild ID, who was referred for problems with anger and underwent assessment for ASD (details about Ben and his family have been altered to maintain

Figure 2 Self-autism mapping

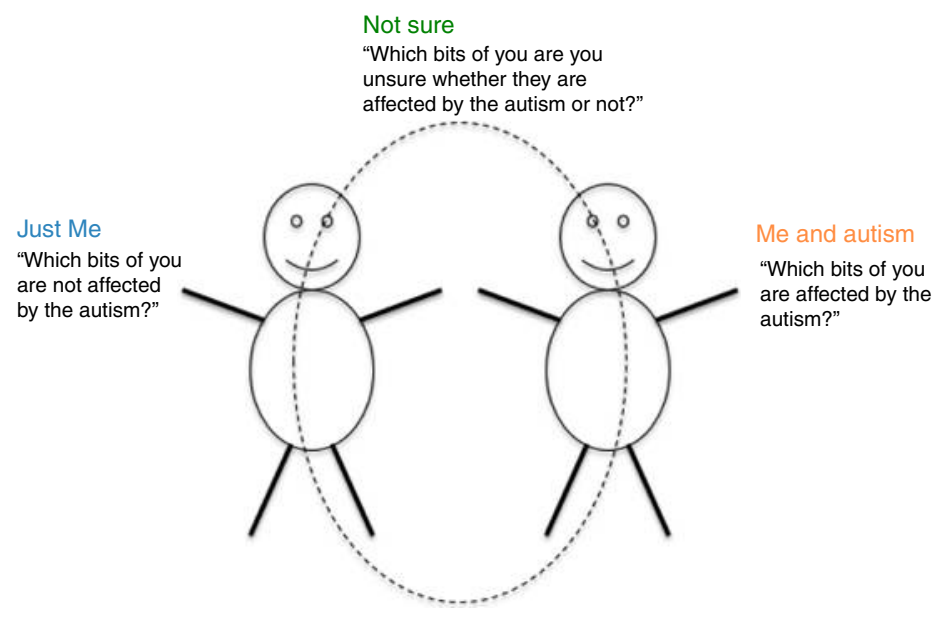


confidentiality). To develop the formulation, Ben's family were asked about a recent, specific situation when he became distressed, which was a time when his mother, Jane, was trying to get him to go to school. A circularity was drawn out (see Figure 3), which illustrated the mutually escalating frustration that occurred between them, as Jane demanded that Ben got out of bed, and he felt less in control, became less flexible, and found it more difficult to regulate his emotions, which made it harder for Jane to respond sensitively to him. This prompted exploration of exceptions, or times where the problem did not occur, and Jane identified that it was easier for Ben to accept requests when she approached him with a calm mindset and had more time to attend to him.

A genogram (see Figure 4) was then drawn out, which allowed the systemic formulation to be developed through exploration of the marital problems between Jane and Ben's father,

\section{Figure 3 Tracking a systemic-attachment process for Jane and Ben}

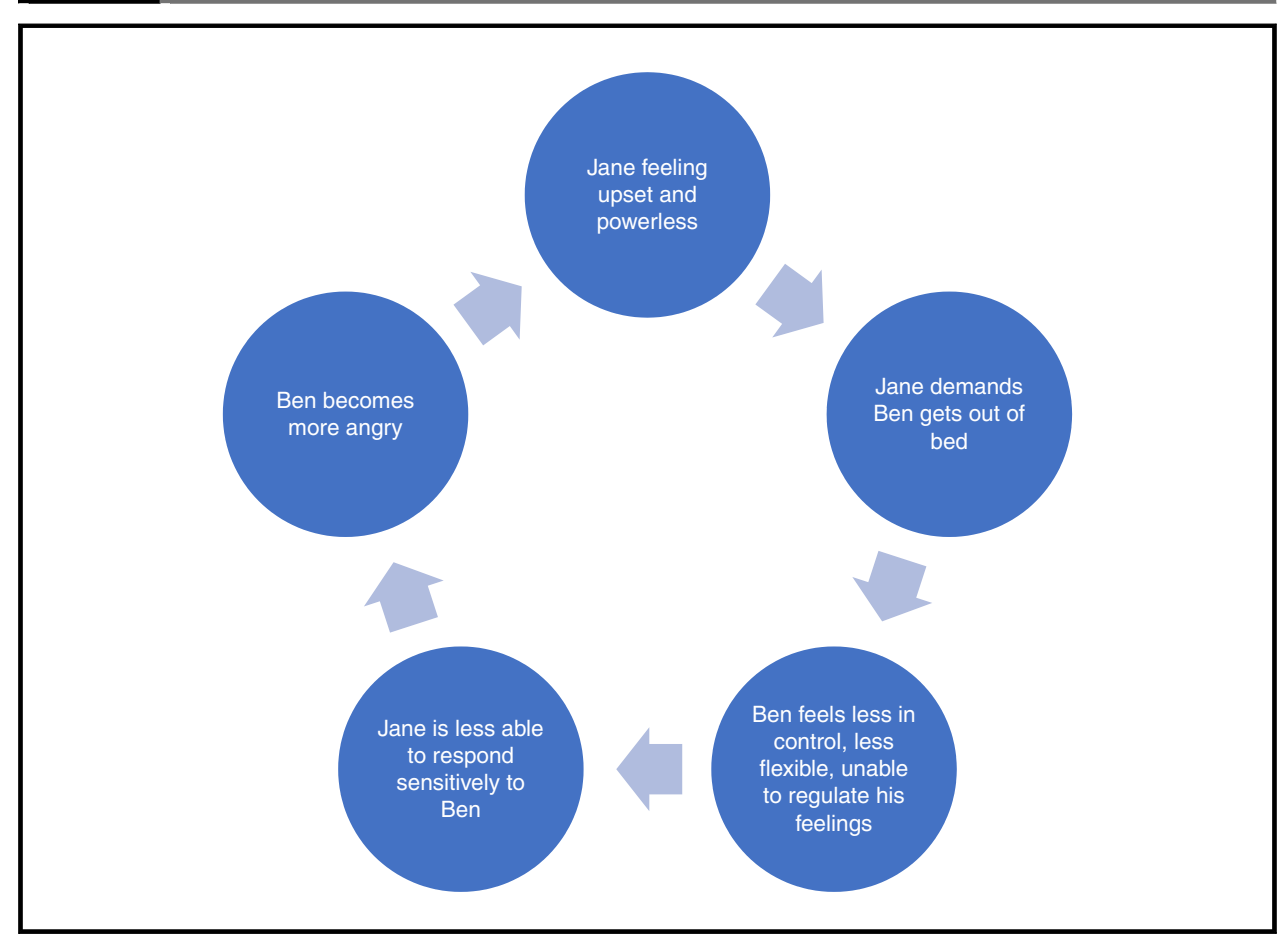

Figure 4 A genogram of Ben's family

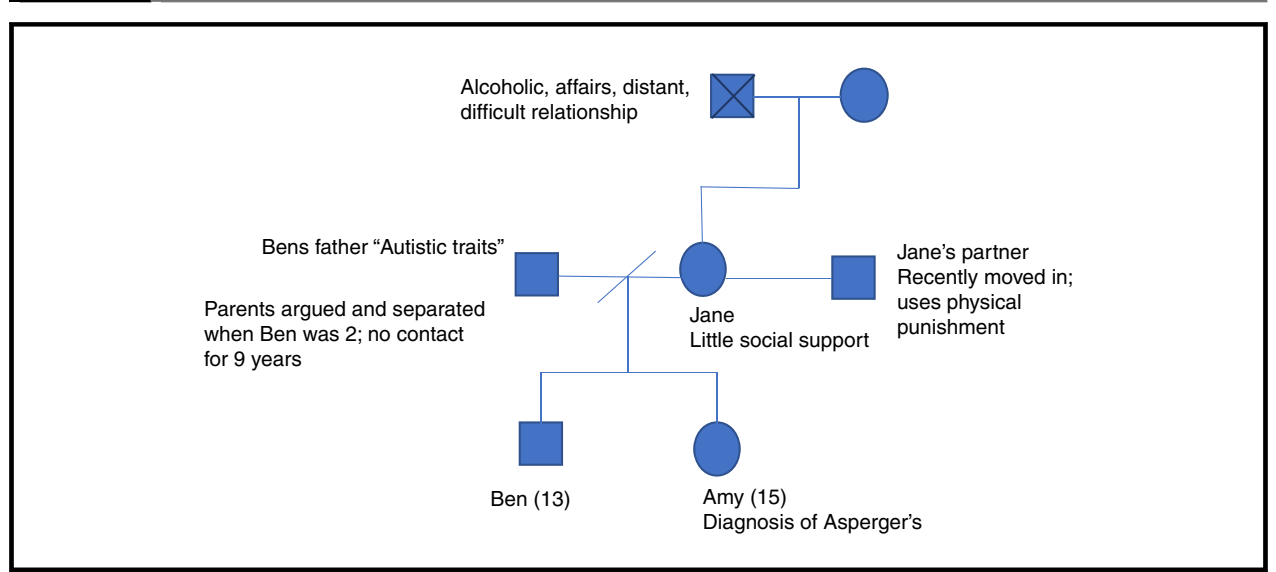


the loss of Ben's maternal grandfather shortly after his birth, and how these affected the degree to which Ben and his parents remained consistently attuned during his early development. The formulation also attempted to integrate the effects of Ben's developmental delay, autistic traits in Ben's father, his parents' later separation, the additional support Ben's older sister needed due to Asperger's syndrome, the lack of social support that was available to Jane, and difficulties with bonding due to Ben's early feeding and sleep difficulties.

Jane appeared to have been "triangulated" in the relationship between her mother and father whilst she was growing up, as she was required to keep secrets about her father's alcohol misuse and extra-marital affairs. This appeared to have restricted the development of her sense of self, and led to a corrective script around wanting her children to be independent. However, Jane was both dependent on her mother for support in raising her children, but also felt frustrated and intruded upon at times by her mother's advice and different approach to parenting. We formulated that this was replicated in Jane's relationship with Ben, as she found it difficult to allow him to develop his independent living skills and do age-appropriate tasks like going to the local shops on his own. The close relationship between Jane and Ben was also influenced by Jane's relationship with her partner, who had recently moved in, as he had little involvement in caring for Ben and they disagreed about his use of physical punishment. Our formulation progressed to consider how Ben is likely to have been confused and distressed by the altered relationships and different approaches to parenting within the family. He appeared to have coped with this by at times avoiding conflict and retreating to his room, and at others becoming frustrated, shouting at his mum or being aggressive towards others at school. This was indicative of him using a "complex" or "mixed" attachment strategy (Dallos and Vetere, 2012).

\section{Discussion}

In this paper, we have discussed how young people are increasingly presenting to services with symptoms of ASD, which are estimated to be co-morbid with other mental health difficulties in more than 63 per cent of cases, and are more commonly associated with insecure attachment patterns than in typically developing children. Clinicians report considerable difficulty in differentiating symptoms of ASD from attachment difficulties, particularly in situations where they occur in complex family circumstances, amongst a myriad of relational problems and stressful life events. We have reviewed evidence suggesting that over 50 per cent of parents with a child diagnosed as having ASD are reported to experience mental health difficulties, which may interact with their child's social communication difficulties to form escalating cycles of distress. Studies have estimated that for between 40 and 70 per cent of parents, the onset of their mental health difficulties predates the birth of their child, indicating that these difficulties are not solely due to the stress of caring for a child with ASD. Our ongoing research using the Adult Attachment Interview with parents has reinforced these findings, and suggested that the proportion could be even higher (McKenzie and Dallos, 2017).

We have also argued that the diagnosis of ASD does not clearly link to which treatment approaches should be used to help young people and their families, and at present, treatment often follows several years of families trying to seek help, which precludes early intervention. We suggest that an integrative formulation approach, incorporating aspects of family systems theory and attachment theory, helps to make sense of how the difficulties associated with ASD and other psychological conditions develop and are influenced by the family context. This may include the different attachment dynamics between family members, the way attachment patterns are transmitted between generations, how problems are viewed by family members, and the way in which transitions in the family lifecycle and events which destabilise the family system are coped with. We believe that this systemic-attachment approach offers a number of advantages over diagnosis alone, particularly if offered early in the development of a child's difficulties, in terms of avoiding an exacerbation of symptoms which may occur for the young person and their family, coordinating the support offered to different family members, and considering how their difficulties relate to one another. 


\section{References}

American Psychiatric Association (2013), Diagnostic and Statistical Manual of Mental Disorders (DSM-5), American Psychiatric Association, Arlington, VA.

Bakermans-Kranenburg, M.J. and van IJzendoorn, M.H. (2009), "The first 10,000 adult attachment interviews: distributions of adult attachment representations in clinical and non-clinical groups", Attachment \& Human Development, Vol. 11 No. 3, pp. 223-63.

Bowlby, J. (1988), A Secure Base, Basic Books, New York, NY.

Byng-Hall, J. (1998), Rewriting Family Scripts: Improvisation and Systems Change, Guilford Press, New York, NY.

Crittenden, P.M., Dallos, R., Landini, A. and Kozlowska, K. (2014), Attachment and Systemic Family Therapy, McGraw-Hill, Maidenhead.

Dallos, R. (2016), "Intervention manual for SAFE (systemic autism-related family enabling): an early intervention for families of children with autism and Asperger syndrome", available at: www.safefamily.org.uk (accessed 27 April 2017).

Dallos, R. and Vetere, A. (2009), Systemic Therapy and Attachment Narratives: Applications in a Range of Clinical Settings, Routledge, Hove.

Dallos, R. and Vetere, A. (2012), "Systems theory, family attachments and processes of triangulation: does the concept of triangulation offer a useful bridge?", Journal of Family Therapy, Vol. 34 No. 2, pp. 117-37.

Dallos, R. and Vetere, A. (2014), "Attachment narrative therapy: patterns, stories and connection", available at: www.acamh.org/knowledge/articles/attachment-narrative-therapy-patterns-stories-and-connections (accessed 9 April 2017).

Daniels, J.L., Forssen, U., Hultman, C.M., Cnattingius, S., Savitz, D.A., Feychting, M. and Sparen, P. (2008), "Parental psychiatric disorders associated with autism spectrum disorders in the offspring", Pediatrics, Vol. 121 No. 5, pp. 1357-62.

Demir, T., Dogangun, B., Karacetin, G., Mukaddes, N.M., Demir, D. and Copur, M. (2008), "Psychiatric disorders and symptoms in mothers of children with autistic disorder", Neurology, Psychiatry and Brain Research, Vol. 15 No. 4, pp. 191-6.

Fombonne, E. (2001), "Is there an epidemic of autism?", Pediatrics, Vol. 107 No. 2, pp. 411-2.

Gaigg, S.B. (2012), "The interplay between emotion and cognition in autism spectrum disorder: implications for developmental theory”, Frontiers in Integrative Neuroscience, Vol. 6, pp. 1-35.

Gillberg, C. (2010), "The ESSENCE in child psychiatry: early symptomatic syndromes eliciting neurodevelopmental clinical examinations", Research in Developmental Disabilities, Vol. 31 No. 6, pp. 1543-51.

Giltaij, H.P., Sterkenburg, P.S. and Schuengel, C. (2015), "Psychiatric diagnostic screening of social maladaptive behaviour in children with mild intellectual disability: differentiating disordered attachment and pervasive developmental disorder behaviour", Journal of Intellectual Disability Research, Vol. 59 No. 2, pp. 138-49.

Giltaij, H.P., Sterkenburg, P.S. and Schuengel, C. (2016), "Adaptive behaviour, comorbid psychiatric symptoms, and attachment disorders", Advances in Mental Health and Intellectual Disabilities, Vol. 10 No. 1 , pp. 82-91.

Green, J., Charman, T., Pickles, A., Wan, M.W., Elsabbagh, M., Slonims, V., Taylor, C., McNally, J., Booth, R., Gliga, T. and Jones, E.J. (2015), "Parent-mediated intervention versus no intervention for infants at high risk of autism: a parallel, single-blind, randomised trial”, The Lancet Psychiatry, Vol. 2 No. 2, pp. 133-40.

Johnstone, L. and Dallos, R. (2013), Formulation in Psychology and Psychotherapy: Making Sense of People's Problems, Routledge, London.

Jokiranta, E., Brown, A.S., Heinimaa, M., Cheslack-Postava, K., Suominen, A. and Sourander, A. (2013), "Parental psychiatric disorders and autism spectrum disorders", Psychiatry Research, Vol. 207 No. 3, pp. 203-11.

Kanner, L. (1943), "Autistic disturbances of affective contact”, Nervous Child, Vol. 2, pp. 217-50.

Kelleher, K.J., Mclnerny, T.K., Gardner, W.P., Childs, G.E. and Wasserman, R.C. (2000), "Increasing identification of psychosocial problems: 1979-1996”, Pediatrics, Vol. 105 No. 6, pp. 1313-21. 
Le Couteur, A., Bailey, A., Goode, S., Pickles, A., Gottesman, I., Robertson, S. and Rutter, M. (1996), "A broader phenotype of autism: the clinical spectrum in twins", Journal of Child Psychology and Psychiatry, Vol. 37 No. 7 , pp. 785-801.

McKenzie, R. and Dallos, R. (in press), "Autism and attachment difficulties: overlap of symptoms, implications and innovative solutions", Clinical Child Psychology and Psychiatry.

McKenzie, R. and Dallos, R. (2016), "I just like Lego!' self-autism mapping as a non-totalising approach", Context, No. 144, pp. 21-3.

McKenzie, R. and Dallos, R. (2017), "Autism and family dynamics", Manuscript in preparation.

Mandy, W. and Lai, M.C. (2016), "Annual research review: the role of the environment in the developmental psychopathology of autism spectrum condition", Journal of Child Psychology and Psychiatry, Vol. 57 No. 3, pp. 271-92.

Marvin, R.S. and Stewart, R.B. (1990), "A family systems framework for the study of attachment", in Greenberg, M.T., Ciccetti, D. and Cummings, E.M. (Eds), Attachment in the Preschool Years: Theory, Research, and Intervention, Chicago University Press, Chicago, IL, pp. 51-86.

Mazefsky, C.A., Folstein, S.E. and Lainhart, J.E. (2008), "Overrepresentation of mood and anxiety disorders in adults with autism and their first-degree relatives: what does it mean?", Autism Research, Vol. 1 No. 3, pp. 193-197.

Midence, K. and O'Neill, M. (1999), "The experience of parents in the diagnosis of autism: a pilot study", Autism, Vol. 3 No. 3, pp. 273-85.

Montague, I., Dallos, R. and McKenzie, R. (in press), "It feels like something difficult is coming back to haunt me': the association between a child's autism spectrum disorder meltdown and a parent's adverse childhood", Clinical Child Psychology and Psychiatry.

Moran, H. (2010), "Clinical observations of the differences between children on the autism spectrum and those with attachment problems: The Coventry Grid", Good Autism Practice, Vol. 11 No. 2, pp. 46-59.

Naber, F.B., Swinkels, S.H., Buitelaar, J.K., Bakermans-Kranenburg, M.J., van IJzendoorn, M.H., Dietz, C., van Daalen, E. and van Engeland, H. (2007), "Attachment in toddlers with autism and other developmental disorders", Journal of Autism and Developmental Disorders, Vol. 37 No. 6, pp. 1123-38.

Nikmat, A.W., Ahmad, M., Oon, N. and Razali, S. (2008), "Stress and psychological wellbeing among parents of children with autism spectrum disorder”, ASEAN Journal of Psychiatry, Vol. 9 No. 2, pp. 65-72.

Pickles, A., Le Couteur, A., Leadbitter, K., Salomone, E., Cole-Fletcher, R., Tobin, H., Gammer, I., Lowry, J., Vamvakas, G., Byford, S. and Aldred, C. (2016), "Parent-mediated social communication therapy for young children with autism (PACT): long-term follow-up of a randomised controlled trial", The Lancet, Vol. 388 No. 10059, pp. 2501-09.

Poslawsky, I.E., Naber, F.B., Bakermans-Kranenburg, M.J., van Daalen, E., van Engeland, H. and van IJzendoorn, M.H. (2015), "Video-feedback intervention to promote positive parenting adapted to autism (VIPP-AUTI): a randomized controlled trial”, Autism, Vol. 19 No. 5, pp. 588-603.

Rhodes, P. (2003), "Behavioural and family systems interventions in developmental disability: towards a contemporary and integrative approach", Journal of Intellectual and Developmental Disability, Vol. 28 No. 1, pp. 51-64.

Roberts, A.L., Lyall, K., Rich-Edwards, J.W., Ascherio, A. and Weisskopf, M.G. (2013), "Association of maternal exposure to childhood abuse with elevated risk for autism in offspring", JAMA Psychiatry, Vol. 70 No. 5, pp. 508-15.

Sasson, N.J., Lam, K.S., Parlier, M., Daniels, J.L. and Piven, J. (2013), "Autism and the broad autism phenotype: familial patterns and intergenerational transmission", Journal of Neurodevelopmental Disorders, Vol. 5 No. 11, pp. 11-8.

Schuengel, C. and Janssen, C.G. (2006), "Attachment, intellectual disabilities and mental health", in Glidden, L.M. (Ed.), International Review of Research in Mental Retardation, Vol. 32, Academic Press, San Diego, CA, pp. 229-60.

Schuengel, C., Schipper, J.C., Sterkenburg, P.S. and Kef, S. (2013), "Attachment, intellectual disabilities and mental health: research, assessment and intervention", Journal of Applied Research in Intellectual Disabilities, Vol. 26 No. 1, pp. 34-46. 
Seskin, L., Feliciano, E., Tippy, G., Yedloutschnig, R., Sossin, K.M. and Yasik, A. (2010), "Attachment and autism: parental attachment representations and relational behaviors in the parent-child dyad", Journal of Abnormal Child Psychology, Vol. 38 No. 7, pp. 949-60.

Siklos, S. and Kerns, K.A. (2006), "Assessing need for social support in parents of children with autism and down syndrome", Journal of Autism and Developmental Disorders, Vol. 36 No. 7, pp. 921-33.

Slade, A. (2009), "Mentalizing the unmentalizable: parenting children on the spectrum", Journal of Infant, Child, and Adolescent Psychotherapy, Vol. 8 No. 1, pp. 7-21.

Solomon, J. and George, C. (2011), Disorganized Attachment and Caregiving, Guilford Press, New York, NY.

Van IJzendoorn, M.H., Rutgers, A.H., Bakermans-Kranenburg, M.J., Swinkels, S.H., Van Daalen, E., Dietz, C., Naber, F., Buitelaar, J.K. and Van Engeland, H. (2007), "Parental sensitivity and attachment in children with autism spectrum disorder: comparison with children with mental retardation, with language delays, and with typical development”, Child Development, Vol. 78 No. 2, pp. 597-608.

Van Steensel, F.J., Bögels, S.M. and de Bruin, E.I. (2013), "Psychiatric comorbidity in children with autism spectrum disorders: a comparison with children with ADHD", Journal of Child and Family Studies, Vol. 22 No. 3, pp. 368-76.

\section{Corresponding author}

Mark Hudson can be contacted at: mark.hudson2@nottshc.nhs.uk

For instructions on how to order reprints of this article, please visit our website:

www.emeraldgrouppublishing.com/licensing/reprints.htm

Or contact us for further details: permissions@emeraldinsight.com 